\title{
Gastrocolic fistulae as a consequence of benign gastric ulcer disease
}

\author{
Jeff Marschall MD, Richard Bigsby MD, Patrik Nechala MD
}

\begin{abstract}
J Marschall, R Bigsby, P Nechala. Gastrocolic fistulae as a consequence of benign gastric ulcer disease. Can J Gastroenterol 2003;17(7):441-443.
\end{abstract}

Gastrocolic fistulae are a rare entity, occurring most commonly in the context of a malignant process or less frequently as a complication of a benign gastric ulcer. Presenting symptoms tend to be nonspecific, but the diagnosis can be confirmed with near certainty by barium enema examination or an upper gastrointestinal series. Although the management of gastrocolic fistulae has historically been surgical, medical management has recently been recommended as the first line of treatment when an underlying malignancy can be excluded.

\section{Fistules gastrocoliques consécutives à l'ulcère gastrique}

Les fistules gastrocoliques sont un phénomène pathologique plutôt rare, mais quand elles se manifestent, elles accompagnent généralement un processus néoplasique et, dans une moindre mesure, l'ulcère gastrique bénin. Les symptômes sont peu spécifiques, mais le diagnostic peut être confirmé par le lavement baryté ou le transit œesogastroduodénal. Bien que le traitement des fistules gastrocoliques ait longtemps reposé sur la chirurgie, on tend désormais à recommander un traitement médicamenteux en première intention après avoir bien sûr écarté tout diagnostic de néoplasie sous-jacente.

Key Words: Complication; Gastrocolic fistula; Gastric ulcer

G astrocolic fistulae have been described as a complication of both benign and malignant conditions; most commonly as a consequence of a fistulizing gastric or colonic carcinoma $(1,2)$. Less frequently, such fistulae have been reported as a complication of benign gastric ulcer disease, with slightly more than 100 cases reported in the literature (2). The management of these fistulae has historically been surgical, although more recently medical therapy has been proposed as a feasible alternative $(3,4)$.

Despite the nonspecific presentation of patients with gastrocolic fistulae, most series in the literature have found the symptomatology to be relatively consistent regardless of the underlying etiology. Several investigational modalities exist to assist the clinician in obtaining the diagnosis with relative certainty (2).

\section{CASE PRESENTATION}

An 82-year-old woman presented with dysphagia, epigastric pain, nausea and feculent vomiting of two months' duration. In addition, she complained of watery diarrhea and admitted to a weight loss of $13.6 \mathrm{~kg}$. She had no previous history of peptic ulcer disease, and denied the use of aspirin or nonsteroidal anti-inflammatory medications, steroids, alcohol or tobacco.

An upper gastrointestinal series suggested the presence of a distal esophageal stricture and a gastroenteric fistula. Subsequent upper gastrointestinal endoscopy revealed a benign esophageal stricture and a greater curvature ulcer suspicious for a fistula. The remainder of the stomach and duode- num were grossly normal. Biopsies of the ulcer showed intestinal metaplasia with no evidence of malignancy, and a rapid urease test for Helicobacter pylori was negative. Gastric antral biopsies were not reviewed for $\mathrm{H}$ pylori, nor was a urea breath test performed. A barium enema confirmed the clinical diagnosis of a gastrocolic fistula, with ensuing colonoscopy failing to disclose a malignant process within the colon (Figure 1 and Figure 2).

The patient received empiric therapy for $H$ pylori, including administration of a proton pump inhibitor twice daily. One month later she continued to have intractable diarrhea, nausea and vomiting. Due to her persistent symptoms and inability to exclude an underlying malignant process, surgical management was recommended. She underwent en bloc resection of the gastrocolic fistula with primary closure of the gastrotomy and primary anastamosis of the transverse colon. Pathological examination revealed the fistula tract to be patent, with no evidence of malignancy. The following day the patient required reoperation for intra-abdominal bleeding; however, a source for the blood loss was not identified. She subsequently had a prolonged course in hospital, but was discharged in good condition. At six-week follow-up she was doing well, with complete resolution of her preoperative symptoms.

\section{DISCUSSION}

Although most commonly the consequence of a malignancy, gastrocolic fistulae complicating benign gastric ulcer disease have been reported in excess of 100 cases $(1,2)$. Less common

Division of General Surgery, Royal University Hospital and St. Paul's Hospital, University of Saskatchewan, Saskatoon, Saskatchewan

Correspondence: Dr Jeff Marschall, Box 7777, St Mary's Hospital, Sechelt, British Columbia VON 3A0. Telephone 604-885-2224,

fax 604-885-8628, e-mail jeffmarschall@hotmail.com

Received for publication December 16, 2002. Accepted March 14, 2003 


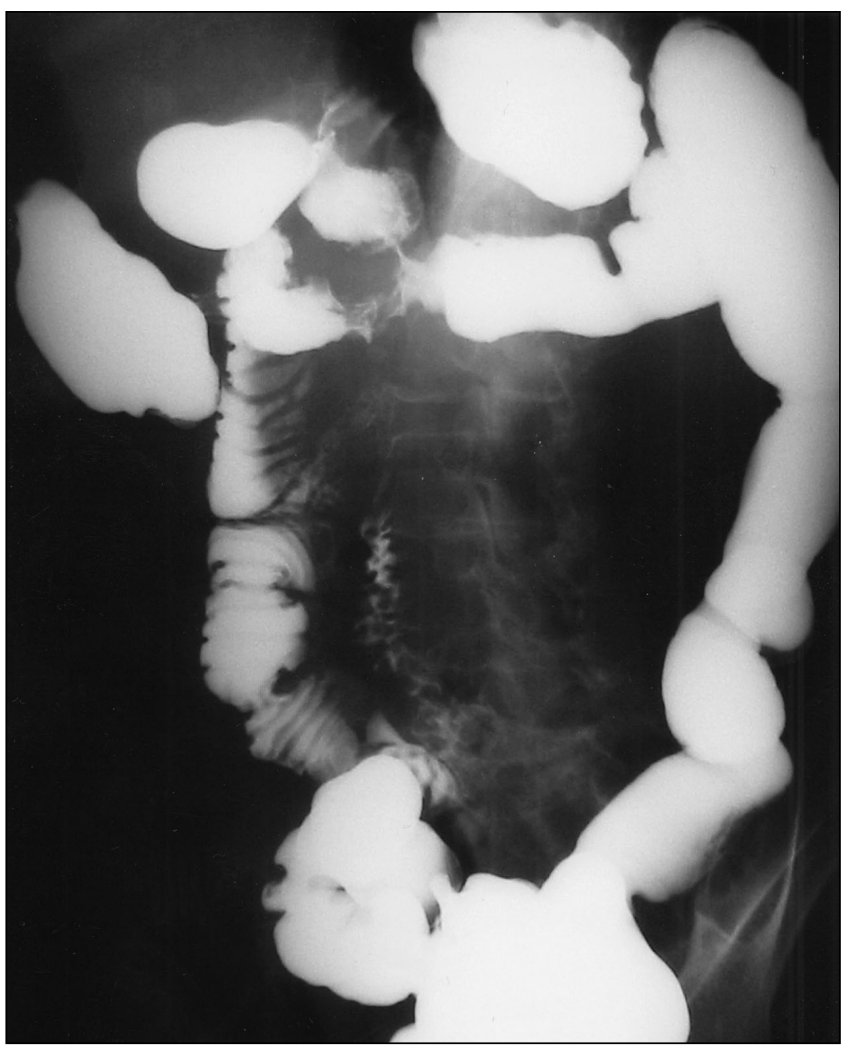

Figure 1) Barium enema demonstrating a gastrocolic fistula with contrast passing from the colon to the stomach

etiologies have included lymphomas of the stomach and colon, Crohn's disease, diverticulitis of the colon and gastrointestinal tuberculosis (5-7).

Haller (8) reported the first case of gastrocolic fistula complicating a gastric carcinoma in 1755, but it was not until 1920 that Firth (9) described the first case of gastrocolic fistula as a complication of gastric ulcer disease. Since then, Soybel and colleagues (2) reviewed 108 cases of gastrocolic fistulae secondary to gastric ulcer disease reported as of 1989 . They found a 2:1 female predominance, and an average age of 50 to 60 years at presentation. Only $50 \%$ of the patients had a documented history of peptic ulcer disease, or prior symptoms consistent with gastric ulceration. Among cases reported between 1979 and 1989, 18 of 24 patients were allegedly using steroids or nonsteroidal anti-inflammatory medications.

Presenting symptoms, although often nonspecific, have been fairly consistent regardless of the underlying etiology. These include weight loss, abdominal pain, diarrhea, feculent emesis, melena or hematochezia, halitosis and rarely perforation $(2,5)$. The investigations available to facilitate a specific diagnosis include upper gastrointestinal series, barium enema, upper and lower gastrointestinal endoscopy and computer tomography. Barium enema has been found to yield the diagnosis in $90 \%$ to $100 \%$ of cases, while endoscopic examination is rarely helpful (10). However, upper and lower gastrointestinal endoscopy function in an important capacity to exclude an underlying malignant etiology.

The management of gastrocolic fistulae has traditionally been surgical, yet medical management has more recently been proposed as the first line of therapy for fistulae arising second-

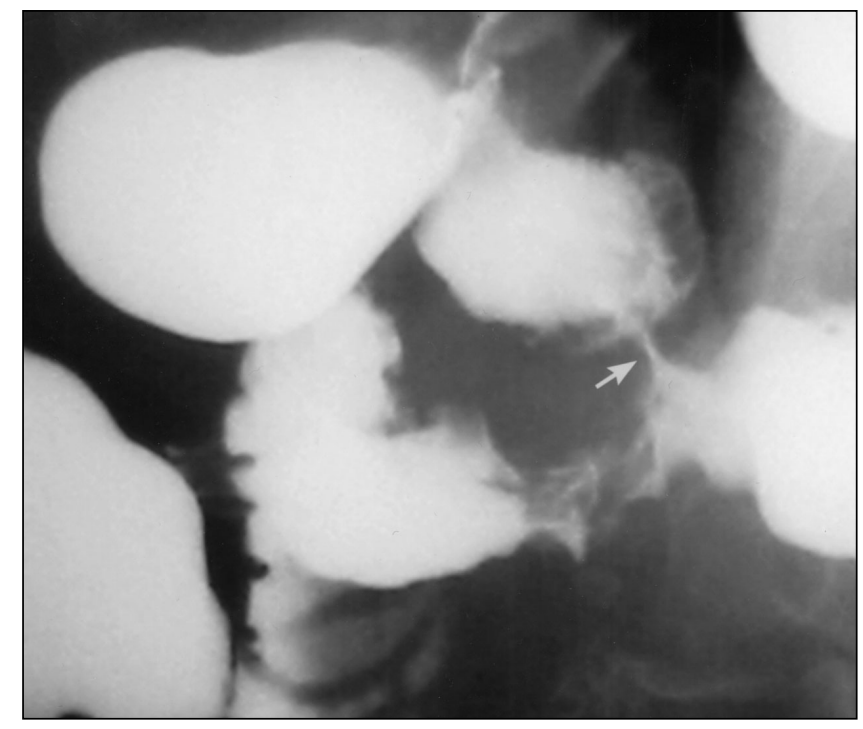

Figure 2) Barium enema further demonstrating the gastrocolic fistula

ary to a benign process $(3,4,11-13)$. When surgical management is indicated, the options include: one-stage en bloc resection of the gastrocolic fistula; simple excision; gastric resection with closure of the colonic wall; and segmental colectomy with closure of the gastrotomy. Medical management consists of cessation of steroids or anti-inflammatory drugs when applicable and prescription of a proton pump inhibitor (3). Additionally, $\mathrm{H}$ pylori eradication therapy should commence either empirically or more definitely if evidence of infection exists. Proponents of the medical approach suggest at least a six-week course of therapy. However, in the absence of ulcer healing, one must consider the possibilities of failure of medical therapy or a misdiagnosis. These patients should be considered for surgical intervention. Finally, a recent case report has outlined the endoscopic management of a gastrocolic fistula to palliate a patient with lymphoma, using human fibrin sealant injections into the gastric and colonic aspects of the fistula tract, with a good result (14).

\section{CONCLUSIONS}

Gastrocolic fistula is a rare diagnosis, and thus may not be considered early in the differential diagnosis. Fortunately, radiological investigations can confirm the diagnosis with a high degree of accuracy, while endoscopic examination is crucial to rule out malignancy. Once a benign etiology has been established, medical management including cessation of nonsteroidal and steroidal anti-inflammatory medications, initiation of acid suppression therapy and $H$ pylori eradication are indicated.

\section{REFERENCES}

1. Tavenor T, Smith S, Sullivan S. Gastrocolic fistula. A review of 15 cases and update of the literature. J Clin Gastroenterol 1993;16:189-91.

2. Soybel DI, Kestenberg A, Brunt EM, Becker JM. Gastrocolic fistula as a complication of benign gastric ulcer: Report of four cases and update of the literature. Br J Surg 1989;76:1298-1300.

3. Thyssen EP, Weinstock LB, Balfe DM, Shatz BA. Medical treatment of benign gastrocolic fistula. Ann Internal Med 1993;118:433-5.

4. Suazo-Barahona J, Gallegos J, Carmona-Sanchez R, Martinez R, 
Robies-Diaz G. Nonsteroidal anti-inflammatory drugs and gastrocolic fistula. J Clin Gastroenterol 1998;26:343-5.

5. Akwari OE, Edis AJ, Wollaeger EE. Gastrocolic fistula complicating benign unoperated gastric ulcer. Report of four cases and review of the literature. Mayo Clin Proc 1976;51:223-30.

6. Perez-Aisa A, Lopez Zaborras J, Sainz Samitier R. The debut of Crohn's disease as a gastrocolic fistula. Gastroenterol Hepatol 1999;22:90-2.

7. Oh PI, Zalev AH, Colapinto ND, Deodhare SS, Brandwein J, Warren RE. Gastrocolic fistula secondary to primary gastric lymphoma. J Clin Gastroenterol 1995;20:45-8.

8. Haller A. Opusula pathologics, partim recusa partim inedita quibus sectiones cadaverum morbosorum potissimum continentur. In: Accendunt Experimenta de Respiratione, Quarta Parle Aucta. Lausanne: Bousequet et Soc, 1755.
9. Firth DA. A case of gastrocolic fistula. Lancet 1920;1:1061.

10. Palnes Hansen C, Lanng C, Christensen A, et al. Gastrocolic fistulas. Acta Chir Scand 1988;154:287-9.

11. Levine MS, Kelly MR, Laufer I, Rubesin SE, Herlinger H. Gastrocolic fistulas: The increasing role of aspirin. Radiology 1993;187:359-61.

12. Britz RS, Mayor-Davies J, Menashe L. Spontaneous closure of a gastrocolic fistula. A case report. S Afr J Surg 1992;30:20-2.

13. Tan CC, Guan R, Chew R, Natarajan S. Closure of a benign gastrocolic fistula on medical management. Singapore Med J 1994;35:423-5.

14. Shand A, Reading S, Ewing J, et al. Palliation of a malignant gastrocolic fistula by endoscopic human fibrin sealant injection. Eur J Gastroenterol Hepatol 1997;9:1009-11. 


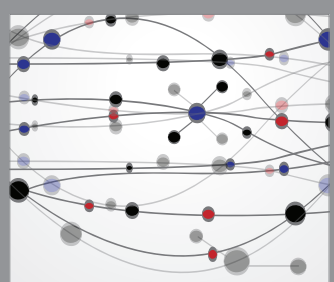

The Scientific World Journal
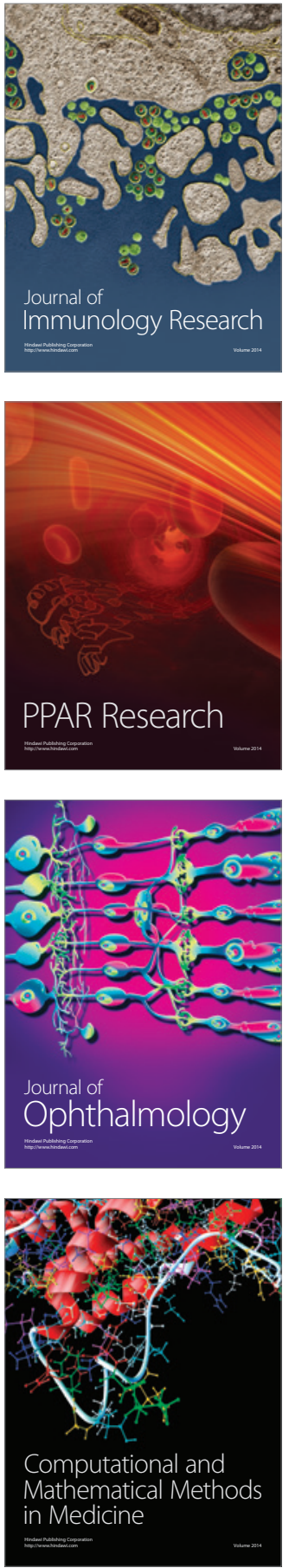

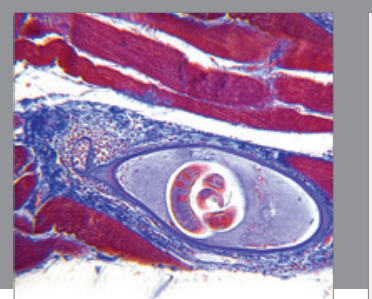

Gastroenterology Research and Practice

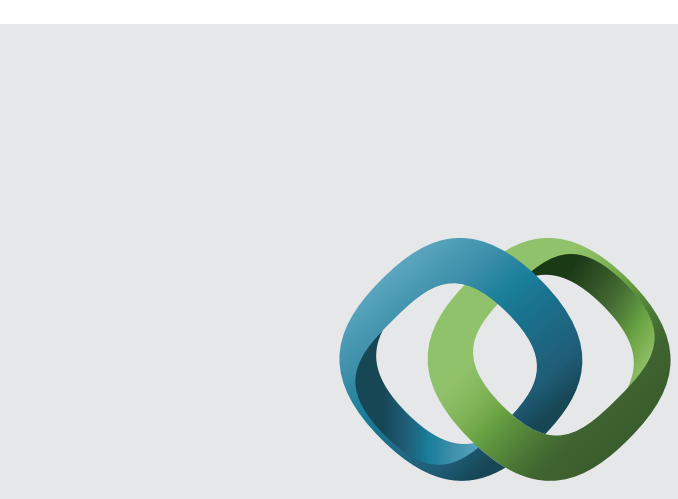

\section{Hindawi}

Submit your manuscripts at

http://www.hindawi.com
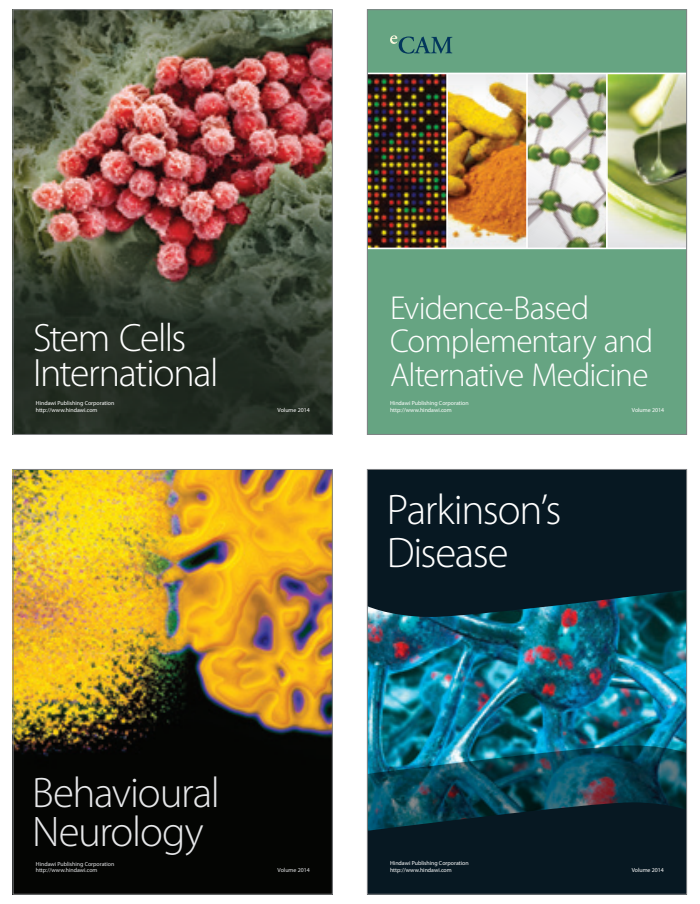
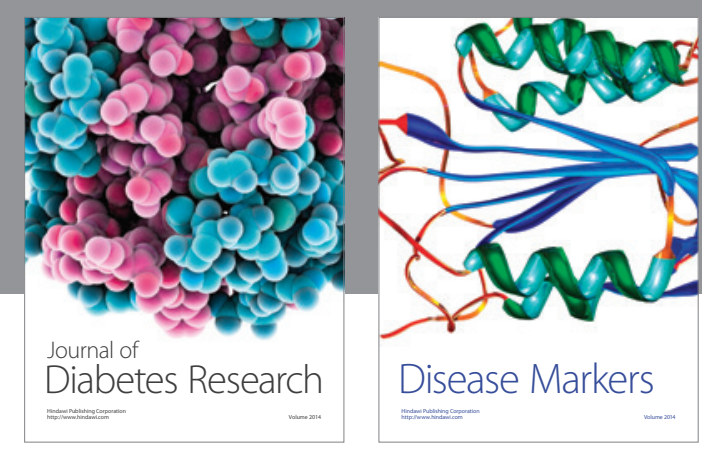

Disease Markers
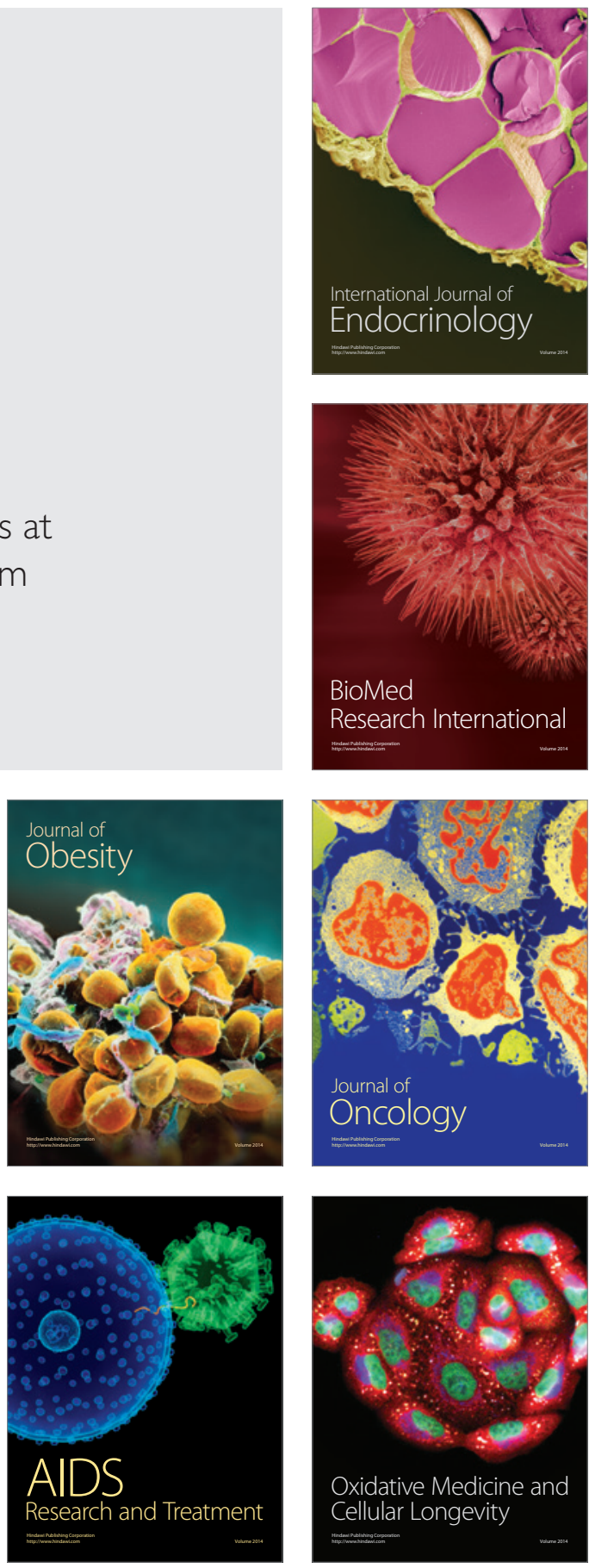